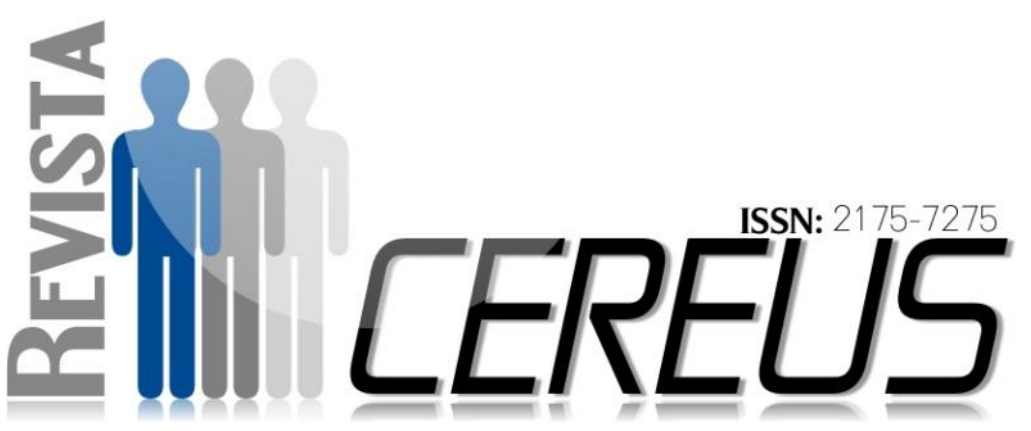

DOI: 10.18605/2175-7275/cereus.v9nep158-171.

\title{
REFLEXOS DO NOVO CÓDIGO DE PROCESSO CIVIL NO PROCESSO DO TRABALHO: ÔNUS DA PROVA
}

SANTOS, Flávia Malachias ${ }^{1}$

DALTOÉ, Adilar ${ }^{2}$

\section{RESUMO}

O presente trabalho pretende analisar os reflexos do Novo Código de Processo Civil no Processo trabalho, com enfoque no ônus da prova. A Consolidação das Leis do Trabalho traz em seu texto legal a previsão de aplicação subsidiária do Código de processo civil ao processo do trabalho nos casos em que há omissão da norma trabalhista e compatibilidade com os princípios do processo do trabalho. Com o Novo Código de Processo Civil (Lei n. ${ }^{\circ}$ 13.105, de 16 de março de 2015), há, em seu artigo 15, previsão de aplicação supletiva e subsidiaria do Código de Processo Civil. O ônus da prova é do autor quanto ao fato constitutivo do seu direito, e do réu quando alegar fato impeditivo, modificativo e extintivo do direito do autor, sendo necessária a inversão do ônus da prova em alguns casos. O legislador de 1973 optou por uma

\footnotetext{
${ }^{1}$ Acadêmica do Curso de Direito do Centro Universitário UNIRG.

${ }^{2}$ Professor e Orientador do Curso de Direito do Centro Universitário UNIRG.
} 
distribuição rígida do ônus da prova, pois acreditava que poderia prever toda e qualquer situação conflituosa. Já o legislador de 2015, optou por dar mais liberdade ao magistrado para fazer distribuição do ônus da prova mais justa para cada caso, trazendo no seu texto legal a Teoria dinâmica de distribuição do ônus da prova, com a intenção de buscar a verdade e a justiça em cada caso concreto, uma vez que percebeu que é impossível ao legislador prever toda e qualquer situação conflituosa. Trazendo assim, maior efetividade as decisões, vez que devem ser baseadas nas provas trazidas aos autos.

Palavras-chave: Ônus da prova. Aplicação supletiva e subsidiária. Inversão do ônus da prova e Teoria dinâmica da distribuição do ônus da prova.

\section{REFLECTIONS OF THE NEW CODE OF CIVIL PROCEDURE IN THE PROCESS OF WORK: BURDEN OF PROOF}

\section{ABSTRACT}

The present work pretends to analyze the reflexes of the New Civil Procedural Law in the Labor Procedural Law, with approach in the burden of proof. The Consolidation of Labor Laws brings in its legal text the prediction of subsidiary application from Civil Procedural Law in Labor Procedural Law in cases that are omission and compatibility with the principles of the labor law. With the New Civil Procedural Law (Law number 13.105, from March 16th, 2015), there's, in its article 15 , prediction of supplementary and subsidiary application from the Civil Procedural Law. To the author belong the burden of proof about the constitutive fact of your rights, and to the defendant belongs the burden of proof about preventive, qualifying and extinctive facts of the author's rights, being 
necessary, sometimes, the inversion of the burden of proof. The legislator from 1973 chosen an inflexible distribution of the burden proof, because he believed that was possible predicts every conflicting situation. Otherwise, the legislator from 2015 , choose to give more independence to the magistrate, by given him the possibility to make a better distribution of the burden of proof for each situation, by bringing in the legal text the Dynamic Distribution of the Burden of Proof Theory, with the intention of collect the truth and the justice in each concrete case, since was notice that is impossible to the legislator predict every conflicting situation. Bringing this, more effective decisions, instead they must be based on the evidence brought to the court.

Key Words: Burden of proof. Supplementary application and subsidiary. Reversal of burden of proof and dynamic theory of distribution of the burden of proof. 


\section{INTRODUÇÃO}

O processo do trabalho possui regras próprias, regras essas que estão contidas na Consolidação das Leis do Trabalho, mas nosso legislador deixou lacunas, que são sanadas com aplicação subsidiária e supletiva do Código de Processo Civil.

Com o advento do Novo Código de Processo Civil (Lei n.. 13.105, de 16 de março de 2015) e sua aplicação supletiva e subsidiária, ocorreram no Processo Trabalho, mudanças que, em primeiro momento, causaram muitas dúvidas aos operadores do Direito Processual Trabalhista, trazendo a tona a presente discussão.

Dentre os diversos questionamentos e dúvidas que surgiram, as provas foram uma das mais comentadas, vez que as provas em um processo são de suma importância, pois toda decisão do juiz deve ser fundamentada, analisando questões exclusivamente de direito, ou questões de direito e de fato, conforme o caso.

As questões de direito são solucionadas com base nas fontes do direito, como leis e princípios, já os fatos são levados pelas partes ao processo e devem ser provados, sendo que os fatos notórios, confessados e incontroversos, não precisam de prova.

A fundamentação do juiz é baseada nas provas que são levadas ao processo, portanto, quando elas não são suficientes, o juiz solicitará diligência para quem obtiver o ônus da prova esclarecer a dúvida.

O artigo 818, da CLT, aplicado em conjunto com o artigo 373, do CPC, nos traz que cabe ao autor provar os fatos constitutivos e ao réu os fatos extintivos, modificativos e impeditivos do direito do autor. Em alguns casos poderão ocorrer a inversão do ônus da prova.

O Código de Processo Civil de 2015 trouxe, expressamente, em seu texto legal, a teoria dinâmica da distribuição do ônus da prova, permitindo buscar, de fato, a verdade e a justiça em cada caso concreto. Com isso o juiz terá mais liberdade e poderá fazer essa distribuição de forma mais justa, de acordo com a capacidade probatória de cada parte, quando produzir uma prova seja impossível ou excessivamente difícil para uma das partes.

Em meio a tantas mudanças no processo civil, houve uma de grande 
relevância para o processo: o ônus da prova. Sabemos que para se resolver uma lide, da forma mais justa possível, são necessárias as provas. Para tanto é preciso saber de quem é o ônus de provar cada fato constitutivo, modificativo e extintivo do direito no

\section{METODOLOGIA}

Pesquisa Teórica (ou Pesquisa Bibliográfica ou Revisão de Literatura) de forma independente, realizada com base em regramentos jurídicos.

Desenvolvida com base no Código civil de 1973 e o Novo Código processo, tanto civil como trabalhista.

Este trabalho tem como finalidade, especificar as reais mudanças do Novo Código de Processo Civil que refletiram no Processo do Trabalho, com enfoque no ônus da prova e a forma como tais mudanças serão aplicadas.

de Processo Civil de 2015, utilizando como material de pesquisa doutrinas, sites, artigos, jurisprudência, súmulas, Orientações Jurisprudenciais, leis e outros meios de divulgação de informação.

\section{APLICAÇÃO SUPLETIVA OU SUBSIDIÁRIA DO CÓDIGO DE PROCESSO CIVIL}

O artigo 769 da CLT tem expressamente, que: "Nos casos omissos, o direito processual comum será fonte subsidiária do direito processual do trabalho, exceto naquilo em que for incompatível com as normas deste Título.". O novo Código de Processo Civil trouxe em seu texto legal o artigo 15, o qual reforça o artigo 769 da CLT, trazendo em seu texto que: "na ausência de normas que regulem processos eleitorais, trabalhistas ou administrativos, as disposições deste código Ihe serão aplicadas supletiva e subsidiariamente.".

A aplicação supletiva do Código de Processo Civil no processo do trabalho ocorre mesmo quando haja lei processual trabalhista que discipline 0 instituto, mas não é completa. Sendo aplicado de forma complementar, de modo que possa ter mais efetividade. Já a aplicação subsidiária apenas 
ocorrerá quando a lei processual trabalhista for omissa.

Para que haja essa aplicação supletiva e subsidiária do processo civil no processo do trabalho, exigem-se dois requisitos cumulativos: omissão e compatibilidade. Sendo a omissão da legislação processual trabalhista e compatibilidade com os princípios trabalhistas.

Para a doutrina clássica a omissão estará presente sempre que houver ausência de lei. Para a doutrina moderna existem três tipos de lacunas: a lacuna normativa ocorre quando em um determinado caso não há norma; a lacuna ontológica há uma norma que não equivale com a realidade; e a lacuna axiológica também há a norma, mas no caso especifico, tornará injusta sua aplicação.

Importante ressaltar que, quando se tratar de processo em fase de execução, aplica-se primeiro a Lei de Execuções Fiscais (6.830/80), nos termos do artigo 889 da CLT.

Art. 889 - Aos trâmites e incidentes do processo da execução são aplicáveis, naquilo em que não contravierem ao presente Título, os preceitos que regem - processo dos executivos fiscais para a cobrança judicial da dívida ativa da Fazenda Pública Federal.
O artigo 15 do CPC não contraria os artigos 769 e 889, da CLT, mas é preciso que haja uma aplicação conjugada destes artigos, pois o CPC exige apenas a omissão da norma e a CLT exige a omissão e a compatibilidade.

\section{PRINCÍPIOS}

Os princípios representam uma base para o ordenamento jurídico, tendo função interpretativa, pois ajudam os operadores do direito na assimilação e aplicação do sistema jurídico; informadora, pois estimula o legislador na elaboração das leis e integrativa, pois na falta de dispositivo legal, serão aplicados por analogia outros princípios e normas gerias do direito.

$\mathrm{Na}$ concepção positivista, os princípios possuíam função meramente subsidiária e supletiva no ordenamento jurídico, tendo apenas a finalidade de completar as lacunas deixadas pelo legislador, mas com o pós-positivismo os princípios adquiriram a condição de norma jurídica, tendo assim, força normativa, atuando autonomamente, podendo inclusive contrariar norma jurídica.

Os princípios têm grande importância no que diz respeito a 
aplicação subsidiária do Código de Processo Civil no Processo do trabalho, pois é um dos requisitos necessários para que haja essa aplicação subsidiária. O doutrinador Mauro Schiavi explica:

Conforme a redação do referido dispositivo legal, são requisitos para a aplicação do Código de Processo Civil ao processo do trabalho: (a) omissão da Consolidação das Leis do Trabalho: quando a Consolidação das Leis do Trabalho e as legislações processuais trabalhistas extravagantes (Leis ns. 5.584/1970 e 7.701/1988) não disciplinam a matéria; (b) compatibilidade com os princípios que regem 0 processo do trabalho. Vale dizer: a norma do Código de Processo Civil, além de ser compatível com as regras que regem o processo do trabalho, deve ser compatível com os princípios que norteiam o Direito Processual do Trabalho, máxime o acesso do trabalhador à justiça.

Diante a importância e integração com a norma jurídica, vale citar alguns dos princípios que norteiam o instituto da prova, dentre os quais se destacam: Contraditório e ampla defesa; Necessidade; Oralidade; Imediação; e Aquisição processual da prova.

\section{ÔNUS DA PROVA}

Para melhor compreensão do termo, ônus vem do latim onus, e significa aquilo que sobrecarrega; carga, peso é uma obrigação que o indivíduo possui de difícil cumprimento. Este termo é bastante utilizado pela área jurídica como: ônus de sucumbência, ônus real e o ônus da prova que é objeto de estudo deste trabalho.

Não há que se falar em ônus da prova, em caso de já haver no processo provas constituídas, uma vez que, as provas pertencem ao processo e não as partes, baseado no princípio da comunhão da prova. Desta forma caso a parte que não possua o ônus da prova, a fizer, a prova dali em diante passa a ser parte do processo, não importando quem a levou aos autos. (MIESSA, 2015, p. 339)

Contudo, há situações em que o processo não possui qualquer prova acostada, sendo necessário que o magistrado realize uma distribuição do ônus da prova, com o intuito de ter meios suficientes para julgar a ação com resolução do mérito. É neste momento que o estudo do ônus da prova tem grande relevância, vez que, pressupõe a insuficiência e/ou inexistência de provas acostadas no processo.

O ônus da prova pode ser subjetivo, visto que busca indagar quem tem o ônus de provar, bem como 
pode ser objetivo, pois é regra de julgamento. (MIESSA, 2015, p. 339)

\section{DISTRIBUIÇÃO DO ÔNUS DA} PROVA

\section{A Consolidação das Leis} Trabalhistas, em seu artigo 818, disciplina a respeito do ônus da prova, especificando que: "a prova das alegações incumbe à parte que as fizer". Mesmo não havendo expressa omissão da CLT a respeito do tema, a doutrina e jurisprudência trabalhista já sedimentaram quanto à necessidade de haver uma complementação pelo Código de Processo Civil, de forma que incumbe ao autor provas os fatos constitutivos e ao réu, os fatos extintivos, modificativos e impeditivos do direito do autor. (CPC, artigo 373)

Importante ressaltar que 0 artigo 373 do Novo Código de Processo Civil manteve a mesma sistemática da distribuição do ônus da prova do antigo CPC, com algumas inovações que serão tratadas posteriormente, ficando seu texto da seguinte forma:

Art. 373. O ônus da prova incumbe: I - ao autor, quanto ao fato constitutivo de seu direito; II - ao réu, quanto à existência de fato impeditivo, modificativo ou extintivo do direito do autor. $\S 1$ ㅇ Nos casos previstos em lei ou diante de peculiaridades da causa relacionadas à impossibilidade ou à excessiva dificuldade de cumprir 0 encargo nos termos do caput ou à maior facilidade de obtenção da prova do fato contrário, poderá o juiz atribuir o ônus da prova de modo diverso, desde que o faça por decisão fundamentada, caso em que deverá dar à parte a oportunidade de se desincumbir do ônus que the foi atribuído. § $2 \circ \mathrm{A}$ decisão prevista no $\S 1$ o deste artigo não pode gerar situação em que a desincumbência do encargo pela parte seja impossível ou excessivamente difícil. § $3 \circ \mathrm{A}$ distribuição diversa do ônus da prova também pode ocorrer por convenção das partes, salvo quando: I - recair sobre direito indisponível da parte; II - tornar excessivamente difícil a uma parte o exercício do direito. § 4o A convenção de que trata o $\S 3$ o pode ser celebrada antes ou durante 0 processo. (CPC/2015, artigo 373)

Cabe apenas ao autor a declaração de fato constitutivo, uma vez que, é dele que nasce a relação jurídica deduzida em juízo, tais como apresentar os requisitos necessários para a configuração da relação de emprego (pessoalidade, pessoa física, onerosidade, subordinação e não eventualidade).

Portanto, ao réu não haverá nenhum ônus de provar quando apenas contestar, negando os fatos constitutivos alegados pelo autor, ficando o autor com o ônus de provar o que alegou em sua Reclamação Trabalhista. 
Nos casos em que o réu alegar em sua defesa novos fatos, com 0 intuito de modificar o direito do autor, extinguir ou impedir que ele nasça, atrairá para si o ônus de provar os fatos alegados. (DIDIER Jr., 2010, p. 80)

$O$ fato extintivo é aquele que exclui direitos e obrigações, põe fim à relação jurídica alegada em juízo pelo autor, o fato impeditivo funda-se na alegação de fato que impede a formação válida da relação jurídica deduzida em juízo, e o fato modificativo pretende alterar a relação deduzida. (MIESSA, 2015, p. 340)

Conforme podemos verificar no artigo 370 do Novo Código de Processo Civil e no artigo 765 da Consolidação das Leis do Trabalho, o magistrado poderá determinar as provas que entender necessárias para 0 julgamento da lide.

Art. 370. Caberá ao juiz, de ofício ou a requerimento da parte, determinar as provas necessárias ao julgamento do mérito. Parágrafo único. $\mathrm{O}$ juiz indeferirá, em decisão fundamentada, as diligências inúteis ou meramente protelatórias. $\quad(\mathrm{CPC} / 2015$, artigo 370)

Art. 765 - Os Juízos e Tribunais do Trabalho terão ampla liberdade na direção do processo e velarão pelo andamento rápido das causas, podendo determinar qualquer diligência necessária ao esclarecimento delas. (CLT, artigo 765)
Em decorrência dos amplos poderes que o magistrado possui na direção de um processo, é preciso que ele tenha um forte desempenho na produção de provas, pois é embasado nelas que fundamentará sua decisão.

\section{INVERSÃO DO ÔNUS DA PROVA}

Em alguns casos haverá a necessidade de se inverter o ônus da prova, sempre mantendo a justiça em sua distribuição. Isso acontecerá de maneira simples, ou seja, o ônus do autor passa a ser do réu.

"O critério a ser utilizado pelo magistrado para a inversão do ônus da prova possui três correntes doutrinarias: (a) a existência de uma presunção em favor de quem, originariamente, teria o encargo; (b) a aplicação subsidiária do art. 6ํㅡㄹ VIII, CDC, dada verossimilhança da alegação do trabalhador ou a sua hipossuficiência; (c) quem seja a parte mais apta, no caso concreto, a se desincumbir do encargo probatório." (NETO \& CAVALCANTE, 2016)

$\mathrm{Na}$ primeira corrente a inversão do ônus da prova pode dar-se por presunção, nos termos do artigo 374, IV, do CPC. Tal presunção de veracidade pode ocorrer de várias formas, sendo uma delas a prevista no 
artigo 232 do Código Civil, no qual se presumem verdadeiras as alegações da parte adversa quando há recusa em se submeter a perícia médica, bem como a prevista no artigo 2.-A da Lei n. $-8.560 / 92$, o qual estabelece que quando houver "a recusa do réu em se submeter ao exame de código genético - DNA gerará a presunção da paternidade, a ser apreciada em conjunto com o contexto probatório".

$\mathrm{Na}$ segunda corrente temos $\mathrm{O}$ artigo 6.. , VII, do Código de defesa do consumidor, que se aplica subsidiariamente ao processo do trabalho, no qual há os casos em que ocorrera a inversão do ônus da prova, os quais sejam: verossímil a alegação; ou quando se tratar de hipossuficiente. Anote-se que a hipossuficiência descrita na norma não é necessariamente a econômica e sim a dificuldade excessiva em produzir a prova.

$\mathrm{Na}$ terceira corrente temos uma inovação trazida com o Novo Código de Processo Civil, na qual basicamente o juiz poderá, definitivamente, ao seu critério, indicar quem deve produzir a prova, conforme cada caso, com base na teoria dinâmica da distribuição do ônus da prova.
TEORIA DINÂMICA DA DISTRIBUIÇÃO DO ÔNUS DA PROVA

O Código de Processo Civil de 1973 optou por uma distribuição rígida do ônus da prova, desconsiderando a peculiaridade de cada caso, pois a forma mais justa de se distribuir o ônus da prova consiste em levar em consideração a capacidade que cada uma das partes tem em produzir provas dos fatos controversos.

"O legislador de 1973 tinha um pensamento de que poderia prever toda e qualquer situação conflituosa, por este motivo deu preferência pela segurança jurídica e pela igualdade puramente formal entre as partes. Deixando o magistrado sem espaço para aplicar outra regra, a não ser a prevista em lei." (MIESSA, apud CARPES, 2010, p. 68),

A inversão do ônus da prova é uma forma que o legislador encontrou para amenizar a rigidez que adotou na distribuição do ônus da prova, em situações bem restritas, as quais já foram estudadas anteriormente.

Mesmo havendo o dispositivo que permite a inversão do ônus da prova, ainda não é suficiente para que haja uma justa distribuição do ônus da prova, mantendo-se estática, ou seja, a partir da posição das partes no 
processo e da natureza do fato controverso, com total desconsideração das peculiaridades do caso concreto e da capacidade das partes produzirem provas dos fatos por ela alegados.

Acontece que, mesmo visando a segurança jurídica, uma distribuição rígida do ônus da prova, pode produzir uma negativa de direito pela ordem jurídica em razão da dificuldade excessiva ou pela impossibilidade de a parte produzir a prova. (MIESSA, 2016, p. 692)

$\mathrm{Na}$ doutrina clássica de direito processual civil, a distribuição dinâmica do ônus da prova, foi ganhando espaço e força, pois entendiam que não deveria ocorrer de forma rígida essa distribuição sob pena de causar prejuízos às partes, devendo-se levar em consideração qual das partes tem melhores condições em produzir a prova.

O Código de Processo Civil de 2015 trouxe no $\S 1 . \circ$ de seu artigo 373, expressamente, a teoria dinâmica do ônus da prova, dizendo que:

Nos casos previstos em lei ou diante de peculiaridades da causa relacionadas à impossibilidade ou à excessiva dificuldade de cumprir o encargo nos termos do caput ou à maior facilidade de obtenção da prova do fato contrário, poderá o juiz atribuir o ônus da prova de modo diverso, desde que o faça por decisão fundamentada, caso em que deverá dar à parte a oportunidade de se desincumbir do ônus que lhe foi atribuído.

Esta inovação trazida pelo novo Código de Processo Civil, adotando em seu texto legal a teoria dinâmica da distribuição do ônus da prova, representa uma evolução da doutrina, uma vez que, o direito processual está mais preocupado em buscar a verdade e a justiça em cada caso, visto que percebeu-se que é impossível ao legislador prever toda e qualquer situação conflituosa.

É válido ressaltar que existem limites para que seja aplicada, pelo juiz, a distribuição dinâmica dos ônus da prova, conforme os parágrafos 1.0 e $2 .$. do artigo 373 do Código de Processo Civil. De forma que, são pressupostos da distribuição do ônus da prova a impossibilidade ou a excessiva dificuldade de uma parte cumprir o seu ônus probatório ou a maior facilidade de obtenção da prova do fato contrário ao que foi alegado por aquela parte, bem como, há necessidade de que tal distribuição seja realizada por decisão fundamentada do juiz, durante a instrução processual, para que a parte tenha oportunidade de se desobrigar do ônus que the foi conferido. 


\section{CONSIDERAÇÕES FINAIS}

Têm-se como contribuição original deste artigo, o estudo do ônus da prova no processo do trabalho, e os reflexos que o Novo Código de Processo Civil trouxe para este instituto.

Tendo em vista que a Consolidação das Leis do Trabalho deixa lacunas quanto ao instituto do ônus da prova, aplica-se supletiva e subsidiariamente o Código de Processo Civil, suprindo qualquer lacuna deixada pelo legislador.

As inovações trazidas pelo novo código de processo civil, que trouxeram para o processo do trabalho maior efetividade, devem ser adotas seja por força do artigo 15, do CPC, seja em razão do artigo 769, da CLT.

A distribuição do ônus da prova não pode ser realizada de forma rígida, mas sim de maneira dinâmica, conforme o caso concreto, assegurando, assim, às partes paridade de armas e maior participação do juiz na condução do processo.

Neste contexto, com base nos artigos 15, do CPC, e 769, da CLT, aplica-se ao processo do trabalho a regra contida no artigo 373 do Novo CPC que nos traz que diante à impossibilidade ou à excessiva dificuldade de cumprir o encargo ou à maior facilidade de obtenção da prova do fato contrário, poderá o juiz atribuir o ônus da prova de modo diverso, desde que o faça por decisão fundamentada, caso em que deverá dar à parte a oportunidade de se desincumbir do ônus que lhe foi atribuído.

Por fim, o legislador, ao adotar no texto legal a distribuição dinâmica do ônus da prova, reconheceu que é impossível prever toda e qualquer situação conflituosa, e que para haver mais justiça nas decisões proferidas é preciso dar maior liberdade para o magistrado conduzir 0 processo conforme cada caso concreto.

\section{REFERÊNCIAS}

BRAGA, Márcia Maria Gonçalves. O ônus da prova do processo do trabalho. Disponível em: <http://www.migalhas.com.br/dePeso/16,Ml51740,31047O+onus+da+prova+no+processo+do+trabalho> Acesso em 28 de setembro de 2016. 
CALCINI, Ricardo Souza. O Novo Processo do Trabalho à luz do NCPC/15: a controvérsia em torno das novas regras processuais trazidas pela IN 39/2016. Disponível em: <http://www.migalhas.com.br/dePeso/16,MI238303,81042O+Novo+Processo+do+Trabalho+a+luz+do+NCPC15+a+controversia+em+torno> Acesso 15/09/2016

CAVALCANTE, Jouberto de Quadros Pessoa. Como se apresenta o ônus da prova no NCPC e seus desdobramentos para o Processo do Trabalho. Disponível em: $<$ http://www.cartaforense.com.br/conteudo/artigos/como-se-apresenta-o-onus-daprova-no-ncpc-e-seus-desdobramentos-para-o-processo-do-trabalho/15520>Acesso em 15 de setembro 2016.

DINAMARCO Cândido Rangel; Ada Pellegrini Grinover; Antonio Carlos de Araujo Cintra, op. cit., p. 70.

GONÇALVES,Marcus Vinicius Rios titulo op. cit., p. 419.

JUNIOR, Fredie Didier. BRAGA, Paula Sarna. OLIVEIRA, Rafael Alexandria de. Curso de direito processual civil: teoria da prova, direito probatório, ações probatórias, decisão, precedente, coisa julgada e antecipação dos efeitos da tutela. 10.ed. Salvador: JusPodivm, 2015. p.106.

LEAL. Juliana Dato. As mudanças do novo CPC e seus reflexos no Processo do Trabalho. Disponível em: <http://julianadato.jusbrasil.com.br/noticias/196993027/asmudancas-do-novo-cpc-e-seus-reflexos-no-processo-do-trabalho $>$ Acesso em 15 de setembro de 2016.

MARCUS Vinicius Rios Gonçalves, Novo Curso de Direito Processual Civil, São Paulo: Saraiva, 2011, p. 413.

MIESSA, Élisson. O Novo Código de Processo Civil e seus reflexos no Processo do Trabalho. 2.ed. Salvador: JusPodivm, 2016.

MIESSA, Élisson. Processo do Trabalho para concursos públicos conforme novo CPC. 2.ed. Salvador: JusPodivm, 2015.

NETO, Francisco Ferreira Jorge. As provas e ônus dinâmico no NCPC e seus desdobramentos para 0 processo do trabalho. Disponível em: $<$ http://genjuridico.com.br/2016/05/10/as-provas-e-onus-dinamico-no-ncpc-e-seusdesdobramentos-para-o-processo-do-trabalho/ > Acesso 15 de setembro de 2016.

RAMOS, François Silva e ALMEIDA, Roberta Pegorari. Do ônus da prova no Direito Processual do Trabalho Brasileiro. Disponível em: <http://www.egov.ufsc.br/portal/conteudo/do-\%C3\%B4nus-da-prova-no-direitoprocessual-do-trabalho-brasileiro> Acesso em 22 de setembro de 2016. 
RAVACHE, Alex Quaresma. O ônus da prova no processo civil moderno. Disponível em: <http://www.conteudojuridico.com.br/artigo,o-onus-da-prova-no-processo-civilmoderno,32422.html> Acesso em 05 de novembro de 2016.

Teresa Arruda Alvim Wambier; José Miguel Garcia Medina, op. cit., p. 251.

WAMBIER Teresa Arruda Alvim; José Miguel Garcia Medina, Processo Civil Moderno - Parte Geral e Processo de Conhecimento, São Paulo: Revista dos Tribunais, 2011, p. 248.

WUNSCH, Guilerme. Novo CPC e reflexos no processo do trabalho: algumas linhas sobre a questão do ônus da prova. Disponível em: $<$ http://emporiododireito.com.br/novo-cpc-e-reflexos-no-processo-do-trabalhoalgumas-linhas-sobre-a-questao-do-onus-da-prova-por-guilherme-wunsch// $>$ Acesso em 15 de setembro de 2016.

Recebido em: 17/11/2016

Aprovado em: 13/11/2017 